Elsevier required licence: (c) 2018. This manuscript version is made available under the CC-BY-NC-ND 4.0 license http://creativecommons.org/licenses/by-nc-nd/4.0/ 
4

5

6

7

8

9

10

\section{Emission Measurement of Diesel Vehicles in Hong Kong through On-Road Remote Sensing: Performance Review and Identification of High-Emitters}

西

(1)

Yuhan Huang ${ }^{1}$, Bruce Organ ${ }^{1,2}$, John L. Zhou, ${ }^{1, *}$, Nic C. Surawski ${ }^{1}$, Guang Hong ${ }^{3}$, Edward F. C. Chan ${ }^{2}$, Yat Shing Yam ${ }^{4}$

(1)

(1)

${ }^{1}$ School of Civil and Environmental Engineering, University of Technology Sydney, NSW 2007, Australia

${ }^{2}$ Jockey Club Heavy Vehicle Emissions Testing and Research Centre, Vocational Training Council, Hong Kong

${ }^{3}$ School of Mechanical and Mechatronic Engineering, University of Technology Sydney, NSW 2007, Australia

${ }^{4}$ Environmental Protection Department, The Government of the Hong Kong Special Administrative Region, Hong Kong

Corresponding author:

Professor John L. Zhou

Email: junliang.zhou@uts.edu.au 


\section{Abstract}

A two-year remote sensing measurement program was carried out in Hong Kong to obtain a large dataset of on-road diesel vehicle emissions. Analysis was performed to evaluate the effect of vehicle manufacture year (1949-2015) and engine size (0.4-20 L) on the emission rates and high-emitters. The results showed that $\mathrm{CO}$ emission rates of larger engine size vehicles were higher than those of small vehicles during the study period, while $\mathrm{HC}$ and $\mathrm{NO}$ were higher before manufacture year 2006 and then became similar levels between manufacture years 2006 and 2015. CO, HC and NO of all vehicles showed an unexpectedly increasing trend during $1998-2004$, in particular $\geq 6001 \mathrm{cc}$ vehicles. However they all decreased steadily in the last decade (2005-2015), except for NO of $\geq 6001 \mathrm{cc}$ vehicles during 2013-2015. The distributions of CO and HC emission rates were highly skewed as the dirtiest $10 \%$ vehicles emitted much higher emissions than all the other vehicles. Moreover, this skewness became more significant for larger engine size or newer vehicles. The results indicated that remote sensing technology would be very effective to screen the $\mathrm{CO}$ and $\mathrm{HC}$ high-emitters and thus control the on-road vehicle emissions, but less effective for controlling NO emissions. No clear correlation was observed between the manufacture year and percentage of high-emitters for $\leq 3000 \mathrm{cc}$ vehicles. However, the percentage of high-emitters decreased with newer manufacture year for larger vehicles. In addition, high-emitters of different pollutants were relatively independent, in particular NO emissions, indicating that high-emitter screening criteria should be defined on a CO-or-HC-or-NO basis, rather than a COand-HC-and-NO basis.

Keywords: Real-world emissions; Diesel vehicles; Engine size; High-emitters; On-road remote sensing 


\section{Introduction}

Vehicle emissions are often believed to be the single largest contributor of atmospheric pollutants (Franco et al., 2013; Liu et al., 2017; Ropkins et al., 2009). To reduce vehicle emissions and improve air quality, new model vehicles are required to comply with the ever tightening emission standards through laboratory testing for type approval, such as the New European Driving Cycle (NEDC). However, the expected reduction in the $\mathrm{NO}_{2}$ concentration at European roadside monitoring sites was not observed with the more stringent standards (Carslaw et al., 2011). In recent years, increasing evidence has been reported on the significant gap in the emissions performance between laboratory testing and real-world driving, in particular diesel vehicles.

Portable emissions measurement system (PEMS) can be used to investigate vehicle emissions performance under real-world driving conditions. Weiss et al. (2011) investigated the on-road emission rates of twelve Euro 3-5 light-duty vehicles using PEMS. The results showed that $\mathrm{CO}, \mathrm{HC}$ and NOx of gasoline vehicles and $\mathrm{HC}$ and $\mathrm{CO}$ of diesel vehicles were generally below the emission limits. However, NOx of diesel vehicles exceeded the limits by $320 \pm 90 \%$ and $\mathrm{CO}_{2}$ surpassed the laboratory levels by $21 \pm 9 \%$. Kousoulidou et al. (2013) tested the emission rates of six Euro 3-5 vehicles under real-world driving and NEDC type-approval conditions using PEMS. They found that gasoline vehicle emissions were well below the emission standards. However, NOx of diesel vehicles complied with the emission limits under NEDC conditions but constantly exceeded the limits under real-world driving conditions. Fu et al. (2013) assessed the NOx emissions of two Euro IV buses by PEMS. Their results indicated that NOx emission factors were 2.6-2.8, 2.3-2.7 and 2.2-2.3 times higher than the emission limits for urban, suburban and freeway driving, respectively. Degraeuwe and Weiss (2017) analysed the PEMS on-road driving emissions of seven Euro 4-6 diesel cars. It was found that the median NOx emissions of NEDCmatched conditions exceeded the limit by $206 \%$, while NOx of all on-road conditions exceeded the limit by $266 \%$. This implied that the narrow NEDC test conditions might be only responsible for part of the elevated on-road diesel NOx emissions.

The gap between real-world driving and type-approval emissions was commonly believed to be increasing with time and the factors responsible for this gap included driving behaviours, vehicle configurations, traffic conditions, road grade and weather which were not well considered in the laboratory testing (Fontaras et al., 2017). Therefore, understanding vehicle emissions under real-world 
driving conditions are critical to address this gap. Although PEMS can measure a long series of emissions data under various real-world driving conditions with acceptable accuracy, the long turnover time of PEMS testing limited its application for a large number of vehicles (Lau et al., 2015) (e.g. ranged from 2 to 12 in above reviewed studies) and thus might not be able to represent a full picture of the onroad vehicles emissions. Additionally, the extra weight of PEMS may bias the measurements, especially for light vehicles (Weiss et al., 2011).

On-road remote sensing provides a non-intrusive method to measure vehicle emissions in a large scale at a relatively low cost. It has been widely used to monitor and control the on-road vehicle emissions. An early long-term remote sensing study showed that $\mathrm{CO}, \mathrm{HC}$ and $\mathrm{NO}$ emissions had decreased significantly over the period of 1997-2007 and the trend was not detailed for gasoline or diesel vehicles (Bishop and Stedman, 2008). However, recent remote sensing studies have identified different emission trends of gasoline and diesel vehicles. Chen and Borken-Kleefeld (2014) measured the emissions of light duty vehicles at one site in Zurich during 2000-2012. The results showed that diesel NOx emissions [ $\mathrm{g} / \mathrm{kg}$ fuel] had actually increased although emission limits had been progressively tightened. However, this discrepancy was not observed for other emissions or gasoline vehicles. Carslaw et al. (Carslaw et al., 2011; Carslaw and Rhys-Tyler, 2013) measured the $\mathrm{NO}$ and $\mathrm{NO}_{2}$ emissions of onroad vehicles using remote sensing in London. They found that only gasoline vehicles showed reduction in $\mathrm{NOx} / \mathrm{CO}_{2}$ over the period of 1985-2012, while diesel vehicles, including those with after-treatment systems designed to reduce NOx, showed little evidence of $\mathrm{NOx} / \mathrm{CO}_{2}$ reduction. Pujadas et al. (2017) investigated the real-world driving emissions of passenger cars in Spain. Their results showed that $\mathrm{CO} / \mathrm{CO}_{2}, \mathrm{HC} / \mathrm{CO}_{2}$ and $\mathrm{NO} / \mathrm{CO}_{2}$ of gasoline vehicles and $\mathrm{CO} / \mathrm{CO}_{2}$ and $\mathrm{HC} / \mathrm{CO}_{2}$ of diesel vehicles were decreasing from pre-Euro to Euro 6 standards, while no $\mathrm{NO} / \mathrm{CO}_{2}$ reduction was observed for diesel vehicles during the same period.

Research into remote sensing in Hong Kong began in 1993 and it has been used for various applications. Chan et al. used remote sensing to develop $\mathrm{CO}, \mathrm{HC}$ and $\mathrm{NO}$ emission factors for gasoline (Chan et al., 2004), diesel (Chan and Ning, 2005) and liquefied petroleum gas (LPG) (Ning and Chan, 2007) vehicles. Lau et al. (2012) used remote sensing to monitor the vehicle emission trends in Hong Kong. It was found that $\mathrm{CO}, \mathrm{HC}$ and $\mathrm{NO}$ emissions $[\mathrm{g} / \mathrm{km}]$ of gasoline and $\mathrm{LPG}$ vehicles were continuously decreasing over the period of 1999-2008, while CO and NO emissions of diesel vehicles 
Department (HKEPD) started using remote sensing as a legislative tool to detect high-emitting vehicles for enforcement purposes (HKEPD, accessed 18.05.2017). The high-emitters detected will be issued with an Emissions Test Notice (ETN) and are required to have the vehicles serviced/repaired and tested at an authorised emissions testing centre within 12 working days. If a vehicle failed the test, the licence would be cancelled and the vehicle would be removed from the road. However, this enforcement programme is currently only applied to gasoline and LPG vehicles, while further investigation is needed to extend this programme to diesel vehicles.

113 The above reviewed remote sensing studies had revealed an unexpected emission trend of diesel vehicles. However, a main limitation was that they were mostly for passenger cars and light commercial vehicles, and the number of diesel emission records in these studies were generally small. Since remote sensing only measures the snapshot emissions of a vehicle in a half second, a large sample size is needed to investigate the average emission trends accurately.

The focus of this paper is to investigate the recent emission trends of diesel vehicles and to identify the potential high-emitters based on on-road remote sensing measurement. The contribution of this study lies in the following three aspects. Firstly, we analysed a sample of 417714 records of on-road diesel vehicle emissions from two years of continuous measurement using remote sensing technology in Hong Kong. The large sample size in this study is believed to present the diesel emission trends in a more statistically accurate manner. Secondly, this study extends the time period and vehicle class covered. The manufacture year of vehicles ranged from 1949 to 2015 and the engine size varied from 0.4 to 20 litres. This large unique database allowed us to analyse the effect of manufacture year (emission standard) and vehicle category (engine size) on emissions. Finally, the emission characteristics of this study could be a good reference for setting up the high-emitting cutpoints of diesel vehicles in Hong Kong (BorkenKleefeld, 2013) and thus help extend the enforcement programme to all the vehicles on road (HKEPD, accessed 18.05.2017). 


\subsection{Remote sensing setup}

In this study, 14 sets of remote sensing equipment were used to collect the data. The measurements were taken at 158 sites across Hong Kong by the HKEPD from 2 January 2014 to 26 January 2016, with 40 sites in Hong Kong Island, 36 sites in Kowloon, 81 sites in New Territories and 1 site in Lantau. Fig. 1 shows the setup of one remote sensing measurement site. A measurement site should be a 5m-width single lane with slight uphill gradient so vehicles are under constant gravity pull and away from traffic lights or intersections to avoid off cycle emissions from hard acceleration/deceleration. The site should also have sufficient traffic volume and vehicle speeds in the range of $7-90 \mathrm{~km} / \mathrm{h}$ for repeatable measurements. Thousands of measurements were needed to develop and determine the site profile. This information was used to determine and validate the locations of the remote sensing units, cameras and support equipment. Two remote sensing units were placed in one measurement site with an approximately 1s separation distance. The second unit was to confirm the measurement consistency and repeatability. When the equipment was powered up and ready, a reference span gas was used to confirm that the units were operating according to the performance specifications. During the measurements, additional calibration checks were performed every two hours with the span gas to ensure results were not drifting outside of the measurement specification limits and the speed profile of vehicles was checked against the site reference information. The data from the previous two hours' measurements was considered valid if these checks were passed.

The ETC-S420 remote sensing system was used to collect the vehicle emissions data, with accuracy of $\pm 15 \%$ of the readings. The system consisted of non-dispersive infrared (NDIR) and ultraviolet (NDUV) sources, detectors, a retroreflector, speed and acceleration sensors and a vehicle plate camera. The NDIR and NDUV beam sources and detectors were placed together on one side of the road and a retroreflector was placed on the other side of the road to reflect the beam from the sources to detectors. The measurement was triggered by the beam being blocked by a passing vehicle. $\mathrm{CO}, \mathrm{CO}_{2}$ and $\mathrm{HC}$ emissions were measured in the IR region and NO emissions were measured in the UV region. Meanwhile, the speed, acceleration and licence plate number of the passing vehicle were also measured and recorded. The registration information of the passing vehicle could be obtained from the vehicle 
plate number, including the make, manufacture year, engine size, fuel type and license class (as defined in Table 1).

\subsection{Data treatment and sampled fleet characteristics}

Since the effective plume path length and the amount of plume measured were influenced by a number of factors such as wind, turbulence, engine size and exhaust pipe height, remote sensing system could only determine the relative concentration ratios of pollutants over $\mathrm{CO}_{2}$ (denoted by $\mathrm{Q}_{\mathrm{P}}$ hereafter where $\mathrm{P}$ could be $\mathrm{CO}, \mathrm{HC}$ or $\mathrm{NO}$ ). For a given exhaust plume, these concentration ratios were constant (Bishop et al., 1989; Burgard et al., 2006). The emission concentrations in percentage (\%) or part per million (ppm), which were the output of the remote sensing system, could be calculated based on a key assumption that the engine was running stoichiometric or rich with no excess oxygen in the exhaust. This was true for conventional gasoline vehicles but not for diesel vehicles. The original remote sensing data showed that most of the $\mathrm{CO}_{2}$ concentrations were in the range of $14.5-15.0 \%$ which was the $\mathrm{CO}_{2}$ concentration of stoichiometric combustion. This indicated that the calculations of absolute emission concentrations were not suitable because diesel engines were mostly operated under lean conditions, even at full load operation (Heywood, 1988). Therefore the emissions data were back calculated to the originally measured emission ratios $\left(\mathrm{Q}_{\mathrm{P}}\right)$ and then converted to emission factors in $[\mathrm{g} / \mathrm{kg}$ fuel] by Eqs. (1)-(3), which removed the assumption for calculating the absolute emission concentrations. matched licence plate number information. Since remote sensing was not weather proof, the number of measurements per month ranged from 1542 (in 9 days of May 2014) to 7337 (in 21 days of March 2015). The number of measurements per day was low because diesel vehicles only accounted for a small percentage (18.5\%) of the total vehicle fleet in Hong Kong (Transport Department of Hong Kong, 2017). This large dataset covered a wide range of on-road diesel vehicles, with manufacture year varying from 1949 to 2015 and engine size from 0.4 to 20 litres. A measurement was considered valid when the vehicle was running at steady speed or positive acceleration and the measured $\mathrm{CO}_{2}$ exhaust plume size 
was sufficient to determine the emission ratios (Carslaw et al., 2011; Chen and Borken-Kleefeld, 2014; 2016). In addition, the vehicle speed was limited up to $75 \mathrm{~km} / \mathrm{h}$ to avoid irregular off-cycle high emission events, which was the speed envelope of the Hong Kong transient emissions testing (HKTET) for emission certificates (Commissioner for Transport, 2012). Among the 417714 records obtained, 105627 records were invalid due to insufficient exhaust plume size (no $\mathrm{CO}_{2}$ reading) and 212072 records were invalid due to speed or acceleration criteria. Finally, 161769 (39\%) valid measurements were remained, which still represented a large sample of the on-road diesel fleet. As shown in Table 1, the total number of licensed diesel vehicles in Hong Kong was 138555 by April 2017 (Transport Department of Hong Kong, 2017). Private cars, medium and heavy goods vehicles, and special purpose vehicles were underrepresented as the number of valid records were much less than the number of licensed vehicles in Hong Kong. On the other hand, light buses, buses and light goods vehicles were well captured in this study with 4.1, 2.1, 1.4 records per vehicle on average, respectively.

Table 2 shows the sampled fleet characteristics by vehicle manufacture year and engine size. The mean manufacture year of the total fleet is 2006.9 and the mean engine size is $4576 \mathrm{cc}$. As shown in Table 2, the majority of the vehicles $(83.6 \%)$ were manufactured in or after 2001 , with $34.4 \%$ in 2011 or newer, $28.7 \%$ in $2006-2010$ and $20.6 \%$ in $2001-2005$. In addition, small vehicles $(\leq 3000 \mathrm{cc})$ have become more and more popular in recent years and the mean engine size has been decreasing with the new manufacture year. This demonstrates the recent engine downsizing trend which is a key technology for reducing both fuel consumption and pollutant emissions (Huang et al., 2015a; Turner et al., 2014). Table 2 also shows that the $\leq 2000 \mathrm{cc}, 5001-6000 \mathrm{cc}$ and $8001-9000 \mathrm{cc}$ vehicles are relatively new, with mean manufacture years of 2012.1, 2010.8 and 2010.4, respectively. The oldest group is the 30014000cc vehicles with a mean manufacture year of 2000.6. Table 3 shows the emission standards and their corresponding effect years for different vehicle types in Hong Kong. Generally, the introduction of each emission standard in Hong Kong was about 2-3 years later than that in the European Union.

\section{Results and Discussion}

\subsection{Effects of manufacture year and engine size on emission trends}

Fig. 2 shows the mean emission factors of $\mathrm{CO}(\mathrm{a}), \mathrm{HC}(\mathrm{b})$ and $\mathrm{NO}$ (c) as a function of manufacture year. The vehicles are categorized into three groups by the engine size of $\leq 3000 \mathrm{cc}, 3001-6000 \mathrm{cc}$ and 
$\geq 6001 \mathrm{cc}$ because they can generate three samples in reasonable sizes and ensure the statistical validity (at least 100 records for each data point (Chen and Borken-Kleefeld, 2016)). In addition, these three ranges of engine size generally correspond to the passenger cars, light goods vehicles, and medium and heavy goods vehicles, respectively. The data point of 1990 includes all the vehicle manufactured in 1990 and before.

As shown in Fig. 2(a), vehicles equipped with larger size engines generally have higher CO emission rates than that with smaller engines. $\mathrm{CO}$ of $\leq 3000 \mathrm{cc}$ vehicles reduce slightly or remain stable, while CO of 3001-6000cc vehicles reduce moderately over the entire period. However, $\mathrm{CO}$ of $\geq 6001 \mathrm{cc}$ vehicles reduce significantly before 1998 and then increase noticeably during 1998-2006 before dropping again in 2006-2015.

Regarding HC emission rates, as shown in Fig. 2(b), larger vehicles show higher emission rates than those of $\leq 3000 \mathrm{cc}$ vehicles before 2006 , but they become comparable after that. The $\leq 3000 \mathrm{cc}$ and $3001-6000 \mathrm{cc}$ vehicles show steady reduction of HC while large vehicles $(\geq 6001 \mathrm{cc})$ show the same trend as that observed in CO, which decrease before 1998, increase during 1998-2006 and then decrease after 2006.

Fig. 2(c) shows that larger vehicles emit significantly higher NO emission rates than those of $\leq 3000 \mathrm{cc}$ vehicles before 2004 , but they have similar NO emission rates after 2005 . For $\leq 3000 \mathrm{cc}$ vehicles, NO emission rates are stable before 1995, decreasing in 1995-1999, increasing in 1999-2006 and decreasing again after 2007. Particularly, a significant jump is observed from 2004 to 2005, making their $\mathrm{NO}$ emission rates comparable to those of $3001-6000 \mathrm{cc}$ and $\geq 6001 \mathrm{cc}$ vehicles. This jump is mainly caused by a significant higher percentage (6.5\%) of NO high-emitters in 2005 vehicles than that of 2004 vehicles (3.2\%). For 3001-6000cc and $\geq 6001 \mathrm{cc}$ vehicles, NO emission rates decrease in 1993-1998, increase in 1998-2002 and then decrease steadily after 2002 except for $\geq 6001 \mathrm{cc}$ vehicles between 2013 and 2015. The present remote sensing system ETC-S420 could only measure NO emission. The total NOx emission rates can be estimated by assuming $\mathrm{NO}_{2} / \mathrm{NOx}$ ratios for different vehicle types. Carslaw and Rhys-Tyler (2013) investigated the total $\mathrm{NOx}$ emissions and $\mathrm{NO}_{2} / \mathrm{NOx}$ ratio of various vehicles using remote sensing. The results showed that $\mathrm{NO}_{2} / \mathrm{NOx}$ varied significantly between car manufacturers, after-treatment technologies and emission standards. Therefore, only the originally measured NO emissions were presented in this study. 
An unexpected trend observed in Fig. 2 is that all the $\mathrm{CO}, \mathrm{HC}$ and $\mathrm{NO}$ emission rates show a more

or less increase during the period of $1998-2004$, in particular $\geq 6001 \mathrm{cc}$ vehicles. This unexpected increasing trend against the automotive emission standards agrees with the results reported previously. Chen and Borken-Kleefeld (2014) studied the diesel NOx emissions [g/kg fuel] from 18000 valid records of diesel cars and 7900 valid records of light commercial vehicles in Zurich with model year from 1985 to 2012 (mostly Euro 1-4). It was found that NOx increased during 1992-2002 and decreased in 2003-2012. Lau et al. (2012) found that CO and NO emissions [g/km] of Hong Kong diesel vehicles increased during 2004-2008. The diesel fleet covered a full range from passenger cars to heavy goods vehicles and buses (74729 valid records), while the model year was only up to 2008 (Euro 4). Bishop et al. (2013) investigated the emissions [g/kg fuel] of heavy-duty diesel vehicles (4293 vehicles) in California with model year up to 2013. They found that NOx increased in 1990-1995 and decreased steadily from 1995 to 2013, and CO increased slightly in 1998-2004 and decreased in 2004-2013. Carslaw et al. (2011) studied an UK diesel fleet with 35705 records, $60 \%$ of which were cars, 34\% were light goods vehicles $(<3.5 t), 2 \%$ were heavy goods vehicles $(>3.5 t)$ and $4 \%$ were buses. The manufacture years were ranged from 1985 to 2010 . The results showed that $\mathrm{NOx} / \mathrm{CO}_{2}$ of heavy goods vehicles tended to decrease, buses trended to increase and passenger cars and light goods vehicles were stable during 2000-2010. Pujadas et al. (2017) analysed the emission trends of pre-Euro to Euro 6 vehicles based on 196985 total measurements, $92 \%$ of which were passenger cars, $7 \%$ were light duty vehicles, $1 \%$ were heavy duty vehicles and $78.5 \%$ were diesel vehicles. They found that while $\mathrm{CO} / \mathrm{CO}_{2}$ and $\mathrm{HC} / \mathrm{CO}_{2}$ of diesel vehicles were decreasing from pre-Euro to Euro 6 standards, $\mathrm{NO} / \mathrm{CO}_{2}$ showed complex trends. $\mathrm{NO} / \mathrm{CO}_{2}$ increased slightly from pre-Euro to Euro 2, was stable from Euro 2 to 3, decreased from Euro 3 to 4 , increased from Euro 4 to 5 and then decreased from Euro 5 to 6 . However, each Euro standard covered several years and thus the detailed trends would have been hidden by the averaged values.

The number of diesel emission records in the above reported studies were generally smaller and they were mostly for passenger cars and light commercial vehicles. In this study, the diesel fleet contained 161769 valid records with manufacture year from 1949 to 2015 and engine size from 0.4 to 20 litres. As shown in Table 1, this fleet consisted of $1 \%$ of private cars, $60 \%$ of light goods vehicles, $11 \%$ of medium goods vehicles, $1 \%$ of heavy goods vehicles, $9 \%$ of light buses and $17 \%$ of buses. The large sample size in this study is believed to present the diesel emission trends in a more statistically 
accurate manner and extend the time period and vehicle class covered. The results in this study show that all CO, HC and NO emission rates are decreasing steadily over the last decade (2005-2015) except for NO of $\geq 6001 \mathrm{cc}$ vehicles which increases again during 2013-2015.

Fig. 3 shows the development of emission rates per vehicle type. For remote sensing data analysis, a large sample size is needed to investigate the average emission trends accurately. Therefore, Fig. 3 only plots the emission rates of light goods vehicles, light buses, medium goods vehicles and buses because the numbers of valid measurements for other vehicle types are too small (as shown in Table 1). Some data points are omitted due to the small number of valid records $(<100)$. The ranges/averages of engine size are 1248-5193/3158cc for light goods vehicles, 2148-4899/3950cc for light buses, 299819688/7273cc for medium goods vehicles and 2998-18024/7734cc for buses. As shown in Fig. 3(a), the $\mathrm{CO}$ emission rates of light goods vehicles, light buses and buses are very similar to each other. Medium goods vehicles show significantly higher $\mathrm{CO}$ emission rates than other vehicle types. Fig. 3(b) shows that medium goods vehicles have slightly higher HC emission rates and all the four vehicle types show steady decrease in HC from 2005 to 2015. Regarding NO emission rates, as shown in Fig. 3(c), light goods vehicles have the lowest emissions before 2005. However, all the vehicle types show similar NO emission rates and decrease steadily after 2005 except buses, whose emission rates increase from 2013 to 2015. Although buses and medium goods vehicles have similar engine size ranges/averages, they show very different $\mathrm{CO}$ and $\mathrm{HC}$ emission rates. This may be caused by the fact that few buses (91) have engines larger than $12000 \mathrm{cc}$, while much more medium goods vehicles (2189) have >12000cc engines. These larger engine size vehicles tend to have higher emission rates, as discussed in Fig. 2.

The light goods vehicles are one of the most popular diesel vehicles in Hong Kong for commercial transport. The Toyota HiAce fleet alone contributes 30732 valid measurements, accounting for 19.0\% of the total records. HiAce vehicles are equipped with a 2982cc diesel direct-injection 1KD-FTV engine launched in 2006 and the gross vehicle weight is $2800 \mathrm{~kg}$. Fig. 4 shows the effect of manufacture year on the average emission factors of the HiAce fleet from 2006 to 2015. This period was compiled with the Euro 4 and 5 standards in which the $\mathrm{CO}, \mathrm{HC}$ and NOx emission limits remain unchanged for 1760$3500 \mathrm{~kg}$ light commercial diesel vehicles. The European emission limits in $[\mathrm{g} / \mathrm{km}]$ are converted to $[\mathrm{g} / \mathrm{kg}$ fuel] by applying a combined fuel economy factor of $8.7[\mathrm{~L} / 100 \mathrm{~km}]$ as given by the manufacturer (Totota, 2017). The NOx limits are converted to NO limits by assuming a $\mathrm{NO}_{2} / \mathrm{NOx}$ ratio of $25 \%$ for 
Euro 4 and 5 vans (Carslaw and Rhys-Tyler, 2013). As shown in Fig. 4, all the three emission rates reduce with the new manufacture year vehicles. Particularly, a significant reduction is observed between 2010 and 2012. This could be explained by the introduction of a new model HiAce in October 2010 when the old HiAce model MK.5-I was replaced by MK.5-II with an upgraded 1KD-FTV engine (AustraianCar.Reviews, accessed 15.05.2017), indicating that engine retrofitting could be effective in reducing vehicle emissions. The $\mathrm{CO}$ emission rates of 2011 or newer vehicles are well below the emission limit and the $\mathrm{HC}$ emission rates of 2015 vehicles generally meet the emission standard. However, the NO emission rates of even the newest manufacture year vehicles are higher than the emission limit. This agrees well with findings of previous PEMS study that $\mathrm{CO}$ and $\mathrm{HC}$ emission rates of diesel vehicles generally remained below the emission limits while NOx emission rates significantly exceeded the limits for Euro 4 and 5 diesel vehicles (Kousoulidou et al., 2013; Weiss et al., 2011). The gap between the real-world driving emission rates and the emission limits becomes larger with older manufacture year vehicles due to the deterioration of combustion and exhaust after-treatment systems.

\subsection{Emission distributions and identification of potential high-emitters}

The emission rates are sorted from the lowest to the highest and then divided into ten equal sized groups (deciles). Fig. 5 shows the mean emission factors of $\mathrm{CO}, \mathrm{HC}$ and $\mathrm{NO}$ in each decile for different engine size and manufacture year vehicles. As shown in Fig. 5, the distributions of CO and HC emission factors are highly skewed so that the dirtiest $10 \%$ vehicles emit much higher emissions than the remaining $90 \%$ of vehicles do. However, the distribution of NO is much less skewed. Fig. 5 also shows that the mean emission rates of each decile are higher for larger engine size or older manufacture year vehicles. However, the $1^{\text {st }}$ to $8^{\text {th }}$ deciles of NO show little difference between $\leq 2004$ and $2005-2009$ vehicles. This could be explained by the fact that diesel NO emission rates showed little evidence of reduction (Carslaw et al., 2011; Carslaw and Rhys-Tyler, 2013; Pujadas et al., 2017) or even increased (Chen and Borken-Kleefeld, 2014; Lau et al., 2012) in recent years in spite of the tightened emission standards.

To quantify the skewness of the emissions distribution, a commonly used parameter is what percentage of the total fleet emissions are emitted by the dirtiest $10 \%$ vehicles. Fig. 6 shows the skewness of diesel emissions by manufacture year and engine size. As shown in Fig. 6, CO and HC emissions are highly dominated by a few dirty vehicles, where $77 \%$ and $54 \%$ of the total fleet CO and 
HC emissions are emitted by the $10 \%$ highest emitting vehicles. However, NO emissions are less skewed where only $30 \%$ of total NO emissions are emitted by the dirtiest $10 \%$ vehicles. The skewness becomes more significant for the newer manufacture year vehicles for all the three emissions. Moreover, this skewness increases for $\mathrm{CO}$ of larger engine size vehicles, but not obvious for $\mathrm{HC}$ and NO. A previous remote sensing study conducted in 2004, 2006 and 2008 showed that $45 \%$ of total CO, 39\% total HC and $24 \%$ of total NO were emitted by the dirtiest $10 \%$ Hong Kong diesel vehicles (Lau et al., 2012). Compared with the previous results, this study demonstrates that the skewed distribution of on-road emissions is getting much more significant for modern diesel vehicles, in particular $\mathrm{CO}$ and $\mathrm{HC}$ emissions. The emission distributions and trends shown in Figs. 5 and 6 indicate that remote sensing technology would be very effective to screen the $\mathrm{CO}$ and $\mathrm{HC}$ high-emitters and thus control the on-road vehicle emissions, in particular large engine size and new manufacture year vehicles. However, remote sensing might be less effective for identifying NO high-emitters since NO is more evenly distributed within the fleet.

Vehicles with high instantaneous emissions do not necessarily mean that they are permanent highemitters, as clean vehicles may have high emissions occasionally. However, if a remote sensing reading is significantly higher than the normal emission level (e.g. the highest $5 \%$ emission concentrations), then the chance of this vehicle being a high-emitter is relatively high. Remote sensing only measures the snapshot emissions of a vehicle in a half second and the accuracy of remote sensing is relatively low comparing with laboratory emissions testing. As a result, remote sensing is unable to distinguish vehicles that nearly-fail or just-exceed the standard limits, and thus it is not aimed to identify all the vehicles that exceed the standard limits (or exceed the limits by certain times). Instead, remote sensing aims to screen out vehicles that significantly exceed the limits, such as the $5 \%$ highest emitting vehicles. This is an effective and efficient emission control measure, as these small percentage of high-emitting vehicles contribute to a significant share of the total fleet emissions. In addition, targeting at a small percentage of high-emitting vehicles could reduce the resistance for implementing such enforcement programs in practice and thus reducing on-road emissions gradually.

Therefore, a fixed threshold of 95th percentile was used in this study to investigate the characteristics of the absolute high-emitting vehicles. Fixed thresholds were also used in previous studies, such as 95th percentile (Pujadas et al., 2017), CO>3\% and HC>500ppm (Lau et al., 2012), and 
CO $>4.5 \%$ (top 3.4\% high-emitters) (Bishop et al., 2000). Under this criterion, the cutpoints are 65.49,

360

9.95 and 29.11 [g/kg fuel] for $\mathrm{CO}, \mathrm{HC}$ and $\mathrm{NO}$, respectively. A vehicle is considered as a high-emitter when it exceeds any one of the three defined cutpoints. By applying the above criteria, 20447 (12.7\%) vehicles are identified as potential high-emitters. These $12.7 \%$ high-emitters contributed $70 \%, 45 \%$ and $23 \%$ of the fleet total $\mathrm{CO}, \mathrm{HC}$ and $\mathrm{NO}$ emissions, respectively. Fig. 7 shows the percentages of highemitters of different engine size vehicles as a function of manufacture year. Generally, $\leq 3000 \mathrm{cc}$ vehicles have lower chance $(8.7 \%$, overall percentage for the whole period covered) being identified as highemitters than that of larger vehicles (13.9\% for 3001-6000cc and $21.0 \%$ for $\geq 6001 \mathrm{cc}$ ). As shown in Fig. 7 , for $\leq 3000 \mathrm{cc}$ vehicles, the percentage of high-emitters has no clear relationship with the vehicle's manufacture year. No statistically significant difference is observed in the percentages between preEuro vehicles (before 1992) and the newest vehicles. This result agrees well with previous study by Pujadas et al. (2017), which reported that the proportion of high-emitting diesel passenger cars $(<2.5$ litres) had no correlation with the Euro standards. However, the same trend does not apply for larger engine size vehicles. As shown in Fig. 7, the percentages of high-emitters within 3001-6000cc and $\geq$ $6001 \mathrm{cc}$ vehicles decrease with the newer manufacture year, except for vehicles $\geq 6001 \mathrm{cc}$ from 1998 2004.

Table 4 shows the number of high-emitting vehicles for one pollutant or at least two pollutants simultaneously. Of the 20447 high-emitters identified, about $40 \%$ of them are high for either CO, HC or NO emissions. However, a high-emitter of one pollutant does not necessarily mean that it is also high of another pollutant. As shown in Table 4, the overlapping of the three emissions is relatively small, especially when it involves NO $(<2.5 \%)$. This is mainly due to their different/conflicting emission formation mechanisms. $\mathrm{HC}$ and $\mathrm{CO}$ are results of incomplete combustion (mainly rich fuel combustion) while NO is formed in high-temperature rich-oxygen condition (slightly lean fuel combustion) (Huang et al., 2015b). The low overlapping percentage of high-emitters of each pollutant has also been reported in previous remote sensing studies for gasoline vehicles (Bishop et al., 2012; Mazzoleni et al., 2004). The little correlation of diesel high-emitters between $\mathrm{CO}, \mathrm{HC}$ and $\mathrm{NO}$ emissions suggests that the screening criteria should be based on a CO-or-HC-or-NO basis (a vehicle will be considered as a highemitter if it exceeds any one of the three cutpoints), rather than a CO-and-HC-and-NO basis (a vehicle will be considered as a high-emitter only when it exceeds all of the three cutpoints). This is because the 
high-emitters of each pollutant are relatively independent and using the later criteria would miss a large number of high-emitters.

\section{Conclusions}

This study aimed to investigate the real-world driving emission characteristics of diesel vehicles in Hong Kong. Remote sensing technology was used to measure the on-road diesel vehicle emissions in a two-year continuous measurement program. The program obtained 417714 measurements with matched vehicle plate number information and 161769 valid records were selected from this large dataset. Analysis was performed to evaluate the effects of vehicle manufacture year (1949-2015) and engine size (0.4-20 litres) on the emission factors and high-emitters. The major conclusions of this study are:

1) $\mathrm{CO}$ emission rates of larger engine size vehicles were higher than that of small vehicles for all the years covered, while $\mathrm{HC}$ and $\mathrm{NO}$ emission rates were higher for the vehicles manufactured before 2006 and then became similar levels between 2006 and 2015. CO, HC and NO showed an unexpected increasing trend during 1998-2004, in particular for vehicles equipped with engines $\geq 6001 \mathrm{cc}$. They all decreased steadily in the past decade (2005-2015), except for NO of $\geq 6001 \mathrm{cc}$ vehicles during 2013-2015. Analysis on the HiAce fleet (the most popular light commercial vehicles in Hong Kong) showed that $\mathrm{CO}$ and $\mathrm{HC}$ of new vehicles were compliant with the emission standards while NO was not. A remarkable reduction of all emissions was observed between 2010 and 2012, indicating that engine retrofit could be an effective strategy for reducing exhaust emissions.

2) The distributions of $\mathrm{CO}$ and $\mathrm{HC}$ emissions were highly skewed so that the dirtiest $10 \%$ vehicles emitted much higher emissions than the rest $90 \%$ vehicles, while NO emissions were much less skewed. $77 \%, 54 \%$ and $30 \%$ of the fleet total $\mathrm{CO}, \mathrm{HC}$ and $\mathrm{NO}$ emissions were emitted by the dirtiest $10 \%$ vehicles. Moreover, this skewed distribution became more significant for larger engine size or newer vehicles. These trends indicated that remote sensing technology would be very effective to screen the $\mathrm{CO}$ and $\mathrm{HC}$ high-emitters and thus control the on-road vehicle emissions, in particular large engine size and new manufacture year vehicles, while it might be less effective for controlling NO emissions.

3) $12.7 \%$ of the vehicles were identified as potential high-emitters under the criteria of the $5 \%$ most polluting of the respective emission factors. No clear correlation was observed between the 
manufacture year and percentage of high-emitters for $\leq 3000 \mathrm{cc}$ vehicles. However, the percentage of high-emitters decreased with newer manufacture year for larger vehicles. Due to different/conflicting emission formation mechanisms, high-emitters showed little overlapping between $\mathrm{CO}, \mathrm{HC}$ and $\mathrm{NO}$, particularly when it involved NO.

\section{Acknowledgements}

The authors would like to thank the Hong Kong Environmental Protection Department (HKEPD)

for providing the remote sensing data used in this study. Authors acknowledge the ownership of data from HKEPD and used it with permission.

\section{References}

AustraianCar.Reviews, accessed 15.05.2017, Review: Toyota MK.5 HiAce van (2005-on), http://australiancar.reviews/reviews.php\#! content $=$ review\&make $=$ Toyota\&model $=$ HiAce \&ge $\underline{n=898}$

Bishop, G.A.; Schuchmann, B.G.; Stedman, D.H., 2013. Heavy-Duty Truck Emissions in the South Coast Air Basin of California. Environmental Science \& Technology 47: 9523-9529

Bishop, G.A.; Schuchmann, B.G.; Stedman, D.H., et al., 2012. Multispecies remote sensing measurements of vehicle emissions on Sherman Way in Van Nuys, California. Journal of the Air \& Waste Management Association 62: 1127-1133

Bishop, G.A.; Starkey, J.R.; Ihlenfeldt, A., et al., 1989. IR Long-Path Photometry: A Remote Sensing Tool for Automobile Emissions. Analytical Chemistry 61: 671A-677A

Bishop, G.A.; Stedman, D.H., 2008. A Decade of On-road Emissions Measurements. Environmental Science \& Technology 42: 1651-1656

Bishop, G.A.; Stedman, D.H.; Hutton, R.B., et al., 2000. Drive-by Motor Vehicle Emissions: Immediate Feedback in Reducing Air Pollution. Environmental Science \& Technology 34: 1110-1116

Borken-Kleefeld, J., 2013, Guidance note about on-road vehicle emissions remote sensing. Vienna Austria: International Council on Clean Transportation

Burgard, D.A.; Bishop, G.A.; Stadtmuller, R.S., et al., 2006. Spectroscopy Applied to On-Road Mobile Source Emissions. Appl Spectrosc 60: 135A-148A

Carslaw, D.C.; Beevers, S.D.; Tate, J.E., et al., 2011. Recent evidence concerning higher NOx emissions from passenger cars and light duty vehicles. Atmospheric Environment 45: 7053-7063

Carslaw, D.C.; Rhys-Tyler, G., 2013. New insights from comprehensive on-road measurements of NOx, $\mathrm{NO} 2$ and NH3 from vehicle emission remote sensing in London, UK. Atmospheric Environment 81: 339-347

Chan, T.L.; Ning, Z., 2005. On-road remote sensing of diesel vehicle emissions measurement and emission factors estimation in Hong Kong. Atmospheric Environment 39: 6843-6856

Chan, T.L.; Ning, Z.; Leung, C.W., et al., 2004. On-road remote sensing of petrol vehicle emissions measurement and emission factors estimation in Hong Kong. Atmospheric Environment 38: 2055-2066

Chen, Y.; Borken-Kleefeld, J., 2014. Real-driving emissions from cars and light commercial vehicles Results from 13 years remote sensing at Zurich/CH. Atmospheric Environment 88: 157-164

Chen, Y.; Borken-Kleefeld, J., 2016. NOx Emissions from Diesel Passenger Cars Worsen with Age. Environmental Science \& Technology 50: 3327-3332

Commissioner for Transport, 2012, Code of Practice for Designated Vehicle Emission Testing Centres (volume 3).

Degraeuwe, B.; Weiss, M., 2017. Does the New European Driving Cycle (NEDC) really fail to capture the NOX emissions of diesel cars in Europe? Environmental Pollution 222: 234-241 
Fontaras, G.; Zacharof, N.-G.; Ciuffo, B., 2017. Fuel consumption and CO2 emissions from passenger cars in Europe - Laboratory versus real-world emissions. Progress in Energy and Combustion Science 60: 97-131

Franco, V.; Kousoulidou, M.; Muntean, M., et al., 2013. Road vehicle emission factors development: A review. Atmospheric Environment 70: 84-97

Fu, M.; Ge, Y.; Wang, X., et al., 2013. NOx emissions from Euro IV busses with SCR systems associated with urban, suburban and freeway driving patterns. Science of The Total Environment 452-453: 222-226

Heywood, J.B., 1988, Internal Combustion Engine Fundamentals ed^eds: McGraw-Hill Book Company

HKEPD, 2015, 2015 Licensed Vehicle by Age and Technology Group Fractions, http://www.epd.gov.hk/epd/sites/default/files/epd/2015_Licensed_Vehicle_by_Age_and_Techn ology_Group_Fractions.rev3.xls

HKEPD, accessed 18.05.2017, Strengthened Emissions Control for Petrol and LPG Vehicles, Environmental Protection Department, The Government of the Hong Kong Special Administrative Region, http://www.epd.gov.hk/epd/english/environmentinhk/air/guide_ref/remote_sensing_Petrol_n_ LPG.htm

Huang, Y.; Hong, G.; Huang, R., 2015a. Investigation to charge cooling effect and combustion characteristics of ethanol direct injection in a gasoline port injection engine. Applied Energy 160: 244-254

Huang, Y.; Hong, G.; Huang, R., 2015b. Numerical investigation to the dual-fuel spray combustion process in an ethanol direct injection plus gasoline port injection (EDI + GPI) engine. Energy Conversion and Management 92: 275-286

Kousoulidou, M.; Fontaras, G.; Ntziachristos, L., et al., 2013. Use of portable emissions measurement system (PEMS) for the development and validation of passenger car emission factors. Atmospheric Environment 64: 329-338

Lau, C.F.; Rakowska, A.; Townsend, T., et al., 2015. Evaluation of diesel fleet emissions and control policies from plume chasing measurements of on-road vehicles. Atmospheric Environment 122: 171-182

Lau, J.; Hung, W.T.; Cheung, C.S., 2012. Observation of increases in emission from modern vehicles over time in Hong Kong using remote sensing. Environmental Pollution 163: 14-23

Liu, Y.-H.; Liao, W.-Y.; Li, L., et al., 2017. Vehicle emission trends in China's Guangdong Province from 1994 to 2014. Science of The Total Environment 586: 512-521

Mazzoleni, C.; Moosmüller, H.; Kuhns, H.D., et al., 2004. Correlation between automotive CO, HC, NO, and PM emission factors from on-road remote sensing: implications for inspection and maintenance programs. Transportation Research Part D: Transport and Environment 9: 477496

Ning, Z.; Chan, T.L., 2007. On-road remote sensing of liquefied petroleum gas (LPG) vehicle emissions measurement and emission factors estimation. Atmospheric Environment 41: 9099-9110

Pujadas, M.; Domínguez-Sáez, A.; De la Fuente, J., 2017. Real-driving emissions of circulating Spanish car fleet in 2015 using RSD Technology. Science of The Total Environment 576: 193-209

Ropkins, K.; Beebe, J.; Li, H., et al., 2009. Real-World Vehicle Exhaust Emissions Monitoring: Review and Critical Discussion. Critical Reviews in Environmental Science and Technology 39: 79-152

Totota, 2017, HiAce specifications of long wheelbase crew van turbo-diesel manual, viewed on 7 July 2017, http://www.toyota.com.au/hiace/specifications/long-wheelbase-crew-van-diesel-manual

Transport Department of Hong Kong, 2017, Table 4.4: Registration and Licensing of Vehicles by Fuel Type (April 2017), http://www.td.gov.hk/filemanager/en/content 4855/table44.pdf

Turner, J.W.G.; Popplewell, A.; Patel, R., et al., 2014. Ultra Boost for Economy: Extending the Limits of Extreme Engine Downsizing. SAE Int J Engines 7: 387-417

Weiss, M.; Bonnel, P.; Hummel, R., et al., 2011. On-Road Emissions of Light-Duty Vehicles in Europe. Environmental Science \& Technology 45: 8575-8581 
514 515 Table 1. Licensed diesel vehicles in Hong Kong by April 2017 (Transport Department of Hong Kong, 2017).

\begin{tabular}{lll}
\hline Type of vehicle & Number of licensed vehicles & Number of valid records \\
\hline Private cars & 8217 & 2411 \\
Light buses & 3402 & 14057 \\
Buses & 13562 & 27955 \\
Light goods vehicles & 69836 & 97238 \\
Medium goods vehicles & 36238 & 18426 \\
Heavy goods vehicles & 5953 & 1457 \\
Special purpose vehicles & 1347 & 225 \\
Total & 138555 & 161769 \\
\hline
\end{tabular}

516

517 Table 2. Fleet sampling characteristics by vehicle manufacture year and engine size.

\begin{tabular}{|c|c|c|c|c|c|c|c|c|c|}
\hline Engine size & $\begin{array}{l}1990 \text { or } \\
\text { before }\end{array}$ & $\begin{array}{l}1991- \\
1995\end{array}$ & $\begin{array}{l}1996- \\
2000\end{array}$ & $\begin{array}{l}2001- \\
2005\end{array}$ & $\begin{array}{l}2006- \\
2010\end{array}$ & $\begin{array}{c}2011 \text { or } \\
\text { newer }\end{array}$ & Mean MY & Total & $\%$ \\
\hline$\leq 2000 \mathrm{cc}$ & 30 & 59 & 0 & 35 & 131 & 2077 & 2012.1 & 2332 & $1.4 \%$ \\
\hline 2001-3000cc & 177 & 2057 & 8004 & 13221 & 24075 & 32614 & 2007.7 & 80148 & $49.5 \%$ \\
\hline $3001-4000 \mathrm{cc}$ & 134 & 865 & 2539 & 2404 & 1175 & 209 & 2000.6 & 7326 & $4.5 \%$ \\
\hline 4001-5000cc & 1 & 935 & 4823 & 11783 & 6932 & 4376 & 2004.6 & 28850 & $17.8 \%$ \\
\hline $5001-6000 \mathrm{cc}$ & 20 & 87 & 67 & 41 & 4289 & 6772 & 2010.8 & 11276 & $7.0 \%$ \\
\hline $6001-7000 \mathrm{cc}$ & 30 & 155 & 120 & 441 & 748 & 502 & 2006.1 & 1996 & $1.2 \%$ \\
\hline 7001-8000cc & 3 & 161 & 773 & 1828 & 3609 & 2624 & 2007.3 & 8998 & $5.6 \%$ \\
\hline 8001-9000cc & 11 & 93 & 157 & 94 & 2994 & 4393 & 2010.4 & 7742 & $4.8 \%$ \\
\hline $9001-10000 \mathrm{cc}$ & 8 & 131 & 1475 & 1362 & 720 & 314 & 2002.2 & 4010 & $2.5 \%$ \\
\hline$\geq 10001 \mathrm{cc}$ & 76 & 330 & 3132 & 2058 & 1698 & 1797 & 2003.9 & 9091 & $5.6 \%$ \\
\hline Mean engine size & 5350 & 4650 & 5283 & 4622 & 4590 & 4256 & $4576 / 2006.9$ & & \\
\hline Total & 490 & 4873 & 21090 & 33267 & 46371 & 55678 & & 161769 & \\
\hline$\%$ & $0.3 \%$ & $3.0 \%$ & $13.0 \%$ & $20.6 \%$ & $28.7 \%$ & $34.4 \%$ & & & $100.0 \%$ \\
\hline
\end{tabular}


519 Table 3. Emission standard and the effect year for diesel vehicles in Hong Kong (HKEPD, 2015). “-”

520 indicates that no vehicles under this emission standard were registered in Hong Kong.

\begin{tabular}{|c|c|c|c|c|c|c|}
\hline $\begin{array}{ll}\text { Vehicle type } & \text { Emission standard }\end{array}$ & Euro 1/I & Euro 2/II & Euro 3/III & Euro 4/IV & Euro $5 / \mathrm{V}$ & Euro 6/VI \\
\hline Private cars & 1995 & - & - & 2008 & 2012 & - \\
\hline Light goods vehicles $(\leq 2.5 \mathrm{t})$ & 1996 & 1999 & 2003 & 2007 & 2012 & - \\
\hline Light goods vehicles (2.5-3.5t) & 1995 & 1998 & 2002 & 2007 & 2012 & - \\
\hline Light goods vehicles (3.5-5.5t) & 1995 & 1997 & 2001 & 2006 & 2012 & - \\
\hline Medium and heavy goods vehicles $(>5.5 t)$ & 1995 & 1997 & 2001 & 2006 & 2012 & - \\
\hline Public light buses & 1995 & 1998 & 2003 & 2006 & 2012 & - \\
\hline Private light buses $(\leq 3.5 \mathrm{t})$ & 1995 & 1998 & 2002 & 2007 & 2013 & - \\
\hline Private light buses $(>3.5 \mathrm{t})$ & 1995 & 1998 & 2003 & 2006 & 2012 & - \\
\hline Non-franchised Buses & 1995 & 1997 & 2001 & 2006 & 2012 & - \\
\hline Single Deck Franchised Buses & 1994 & 1996 & 2003 & 2007 & 2010 & - \\
\hline Double Deck Franchised Buses & 1993 & 1997 & 2001 & 2006 & 2010 & 2014 \\
\hline
\end{tabular}

521

522 Table 4. Correlations of diesel high-emitters between different pollutants.

\begin{tabular}{lll}
\hline Criteria & No. of high-emitters & $\%$ of all high-emitters \\
\hline High CO & 8089 & $39.6 \%$ \\
High HC & 8078 & $39.5 \%$ \\
High NO & 8093 & $39.6 \%$ \\
High CO and HC & 3164 & $15.5 \%$ \\
High CO and NO & 285 & $1.4 \%$ \\
High HC and NO & 476 & $2.3 \%$ \\
High CO and HC and NO & 112 & $0.5 \%$ \\
\hline
\end{tabular}




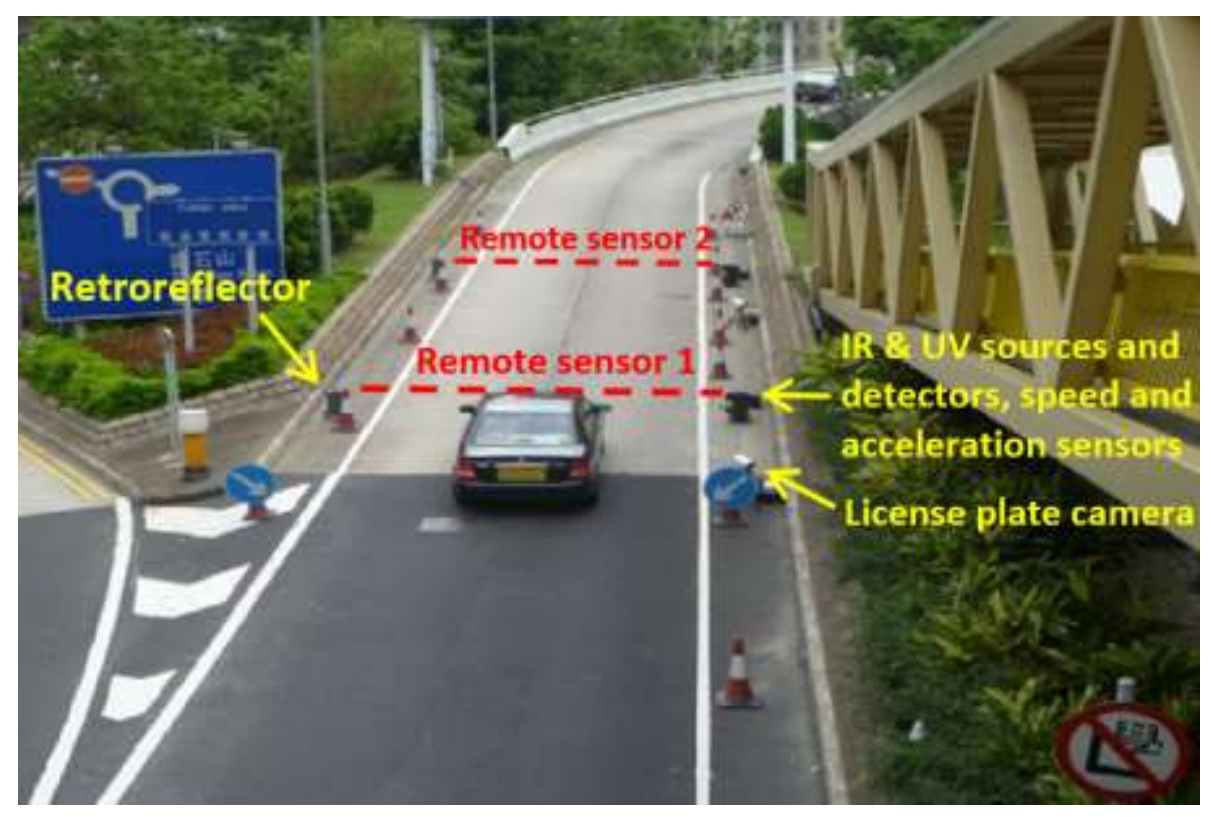

Fig. 1. Typical setup of on-road remote sensing measurement site.
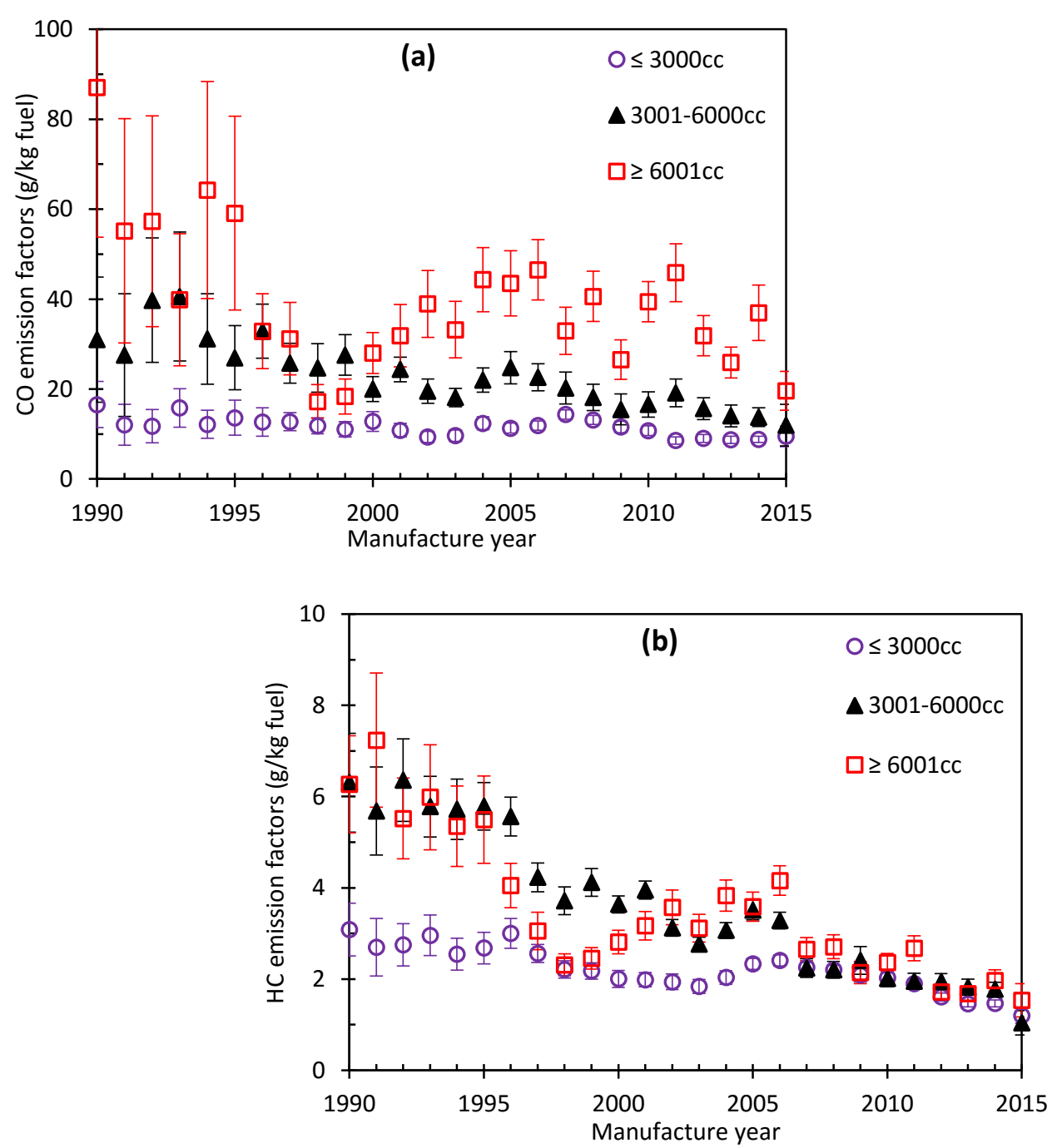


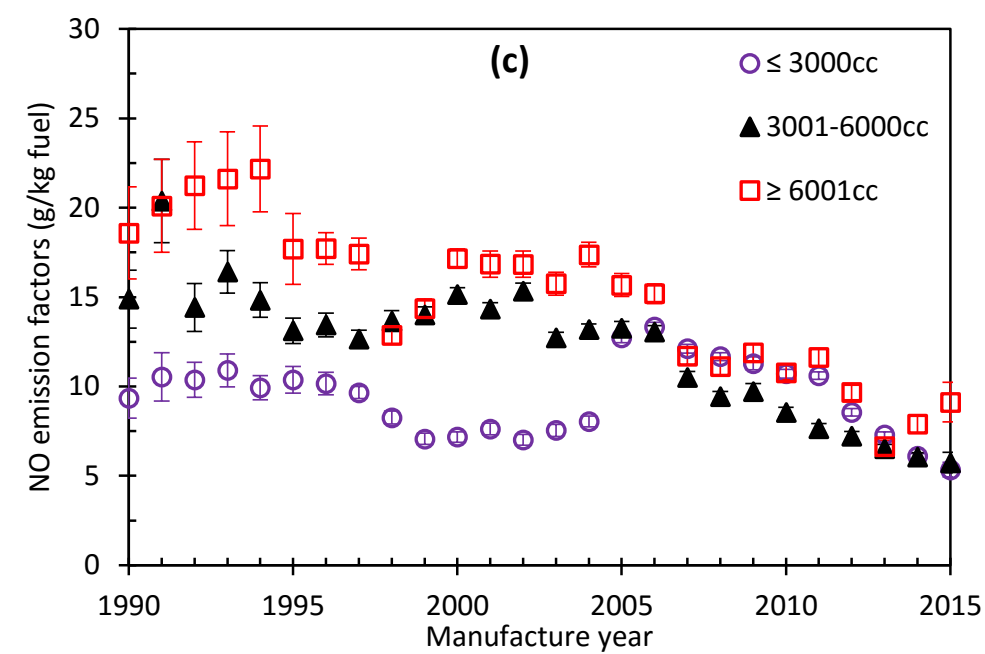

Fig. 2. Mean emission factors of $\mathrm{CO}$ (a), HC (b) and NO (c) of different engine size vehicles by manufacture year. Error bars indicate $95 \%$ confidence interval over the mean.
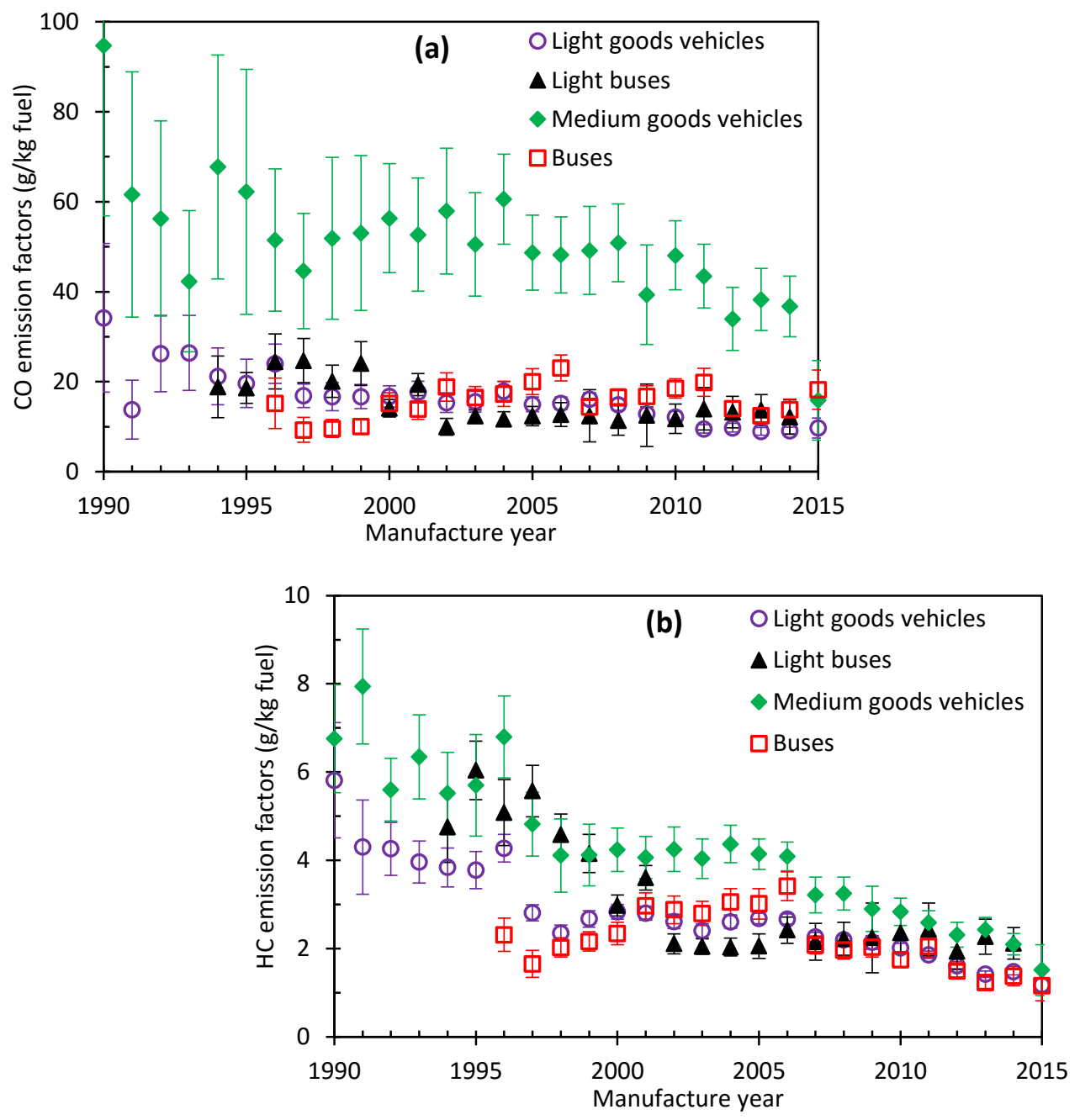


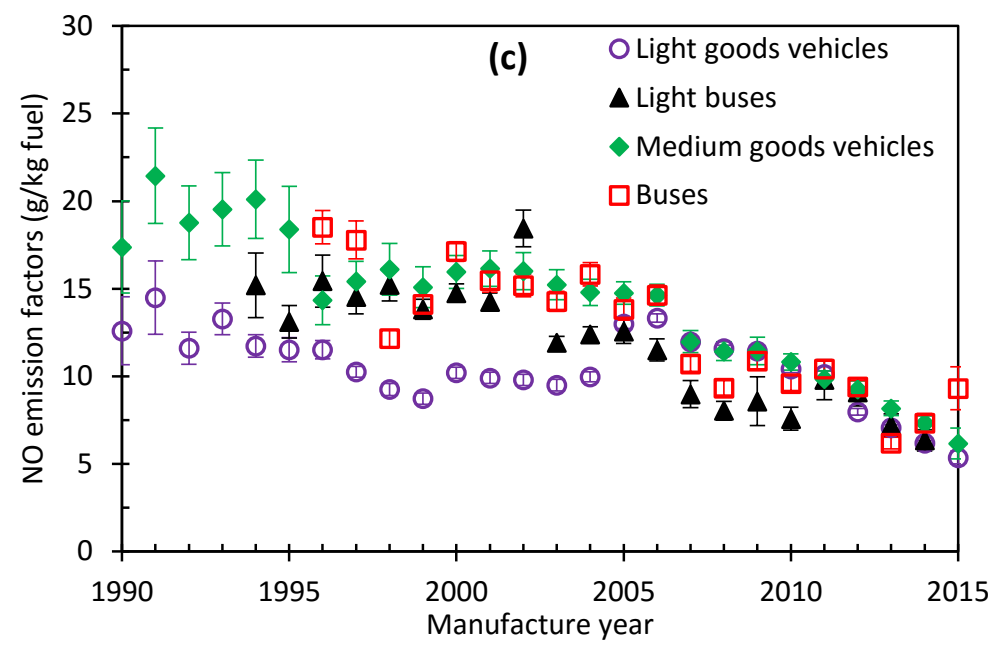

Fig. 3. Mean emission factors of $\mathrm{CO}(\mathrm{a}), \mathrm{HC}(\mathrm{b})$ and $\mathrm{NO}$ (c) of different vehicle types by manufacture year. Error bars indicate $95 \%$ confidence interval over the mean.

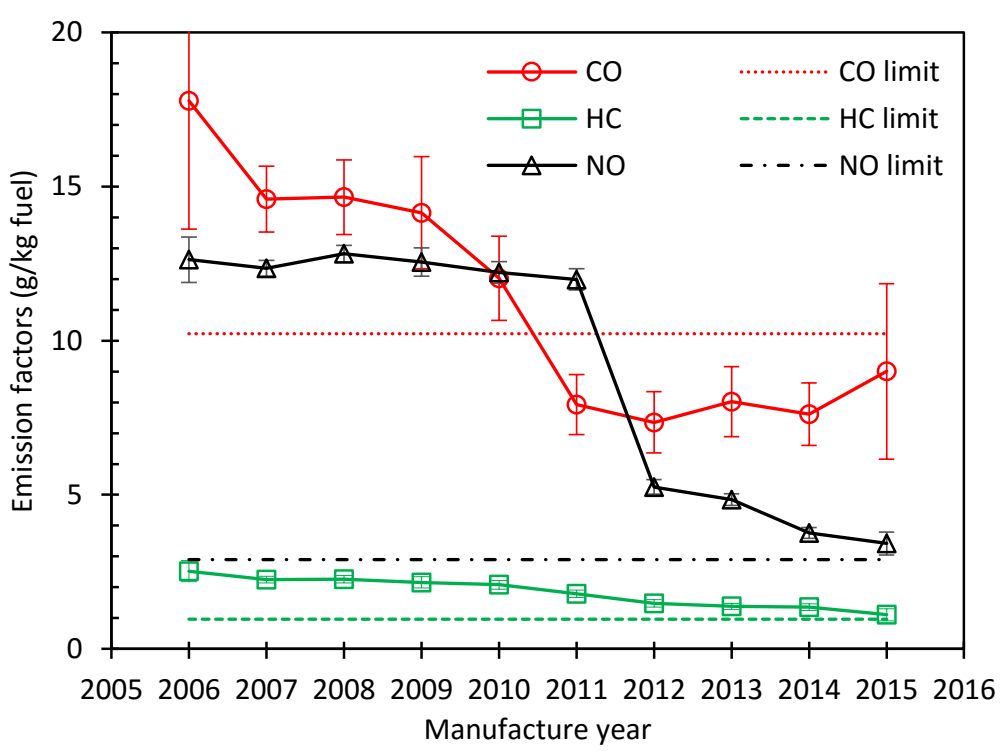

537 Fig. 4. Mean emission factors of Toyota HiAce fleet by manufacture year. Error bars indicate $95 \%$ confidence interval over the mean.
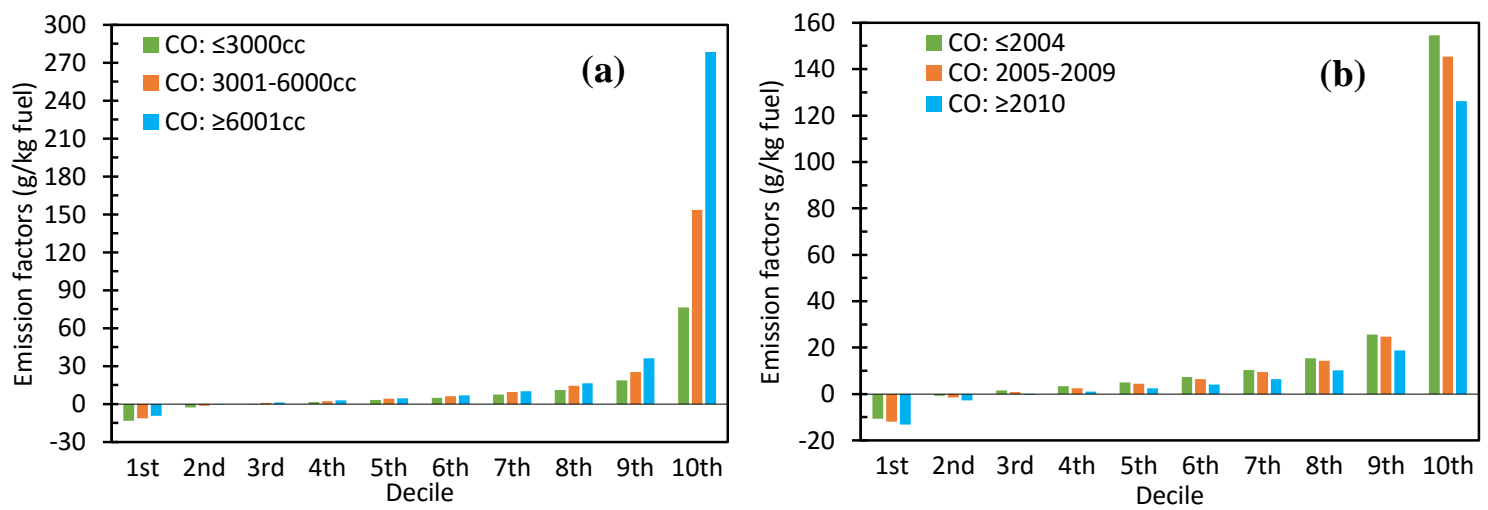

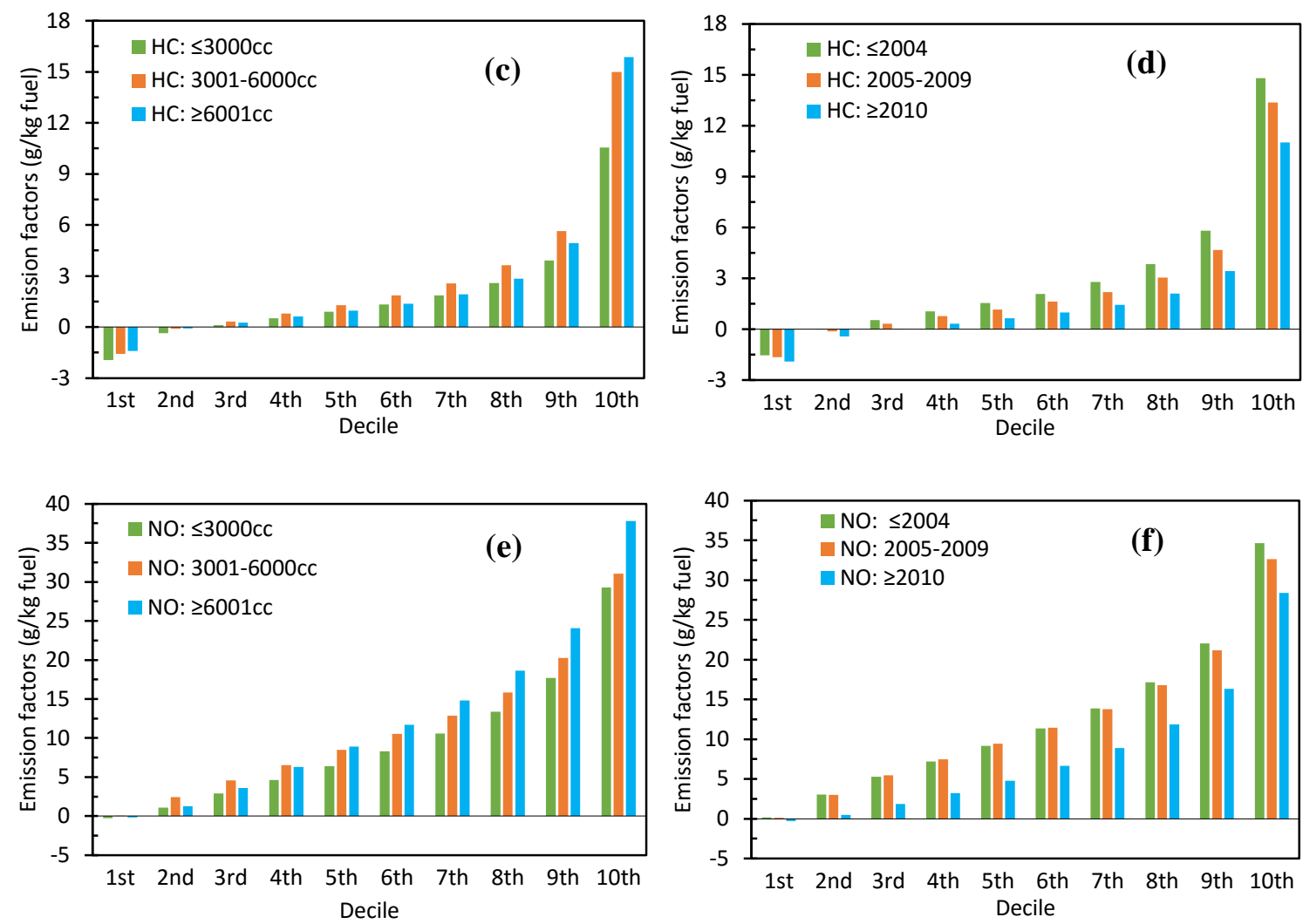

542 Fig. 5. Mean emission factors of each decile for different engine size and manufacture year vehicles:

(a) $\mathrm{CO}$ by engine size, (b) $\mathrm{CO}$ by manufacture year, (c) $\mathrm{HC}$ by engine size, (d) $\mathrm{HC}$ by manufacture year, (e) NO by engine size and (f) NO by manufacture year.

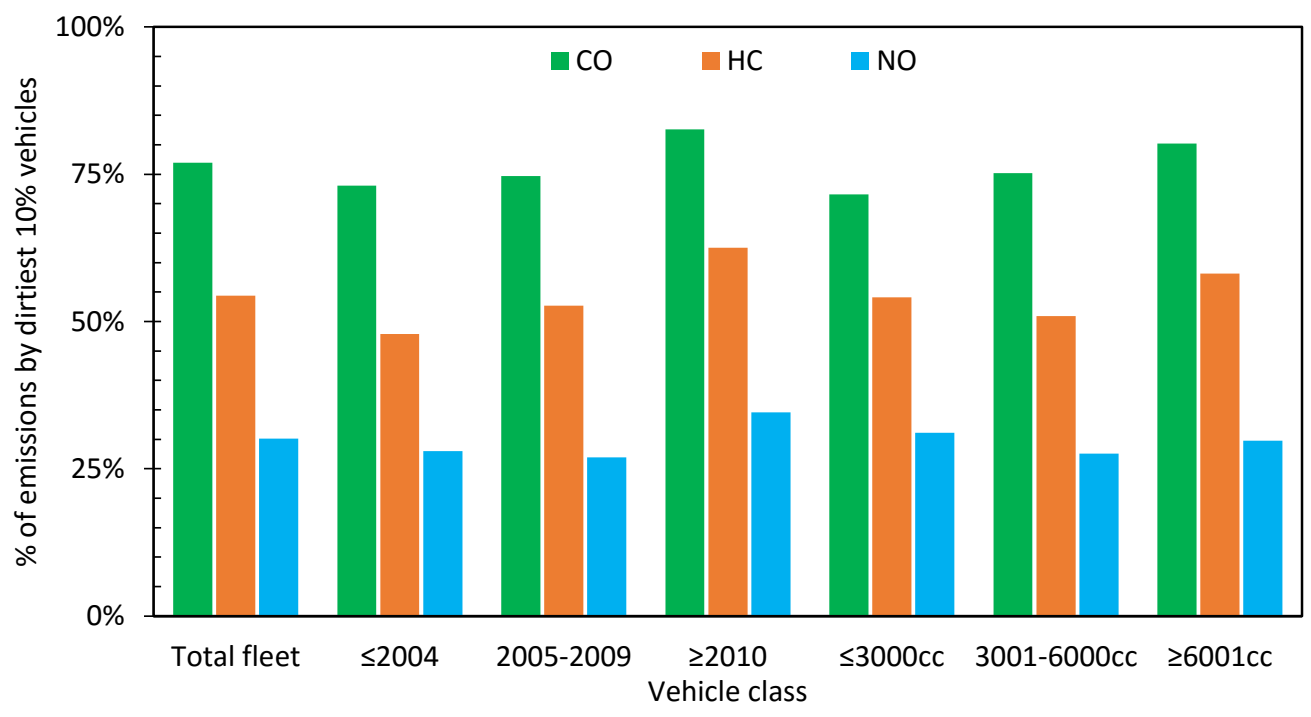

Fig. 6. Percentages of emissions contributed by the dirtiest $10 \%$ vehicles. 


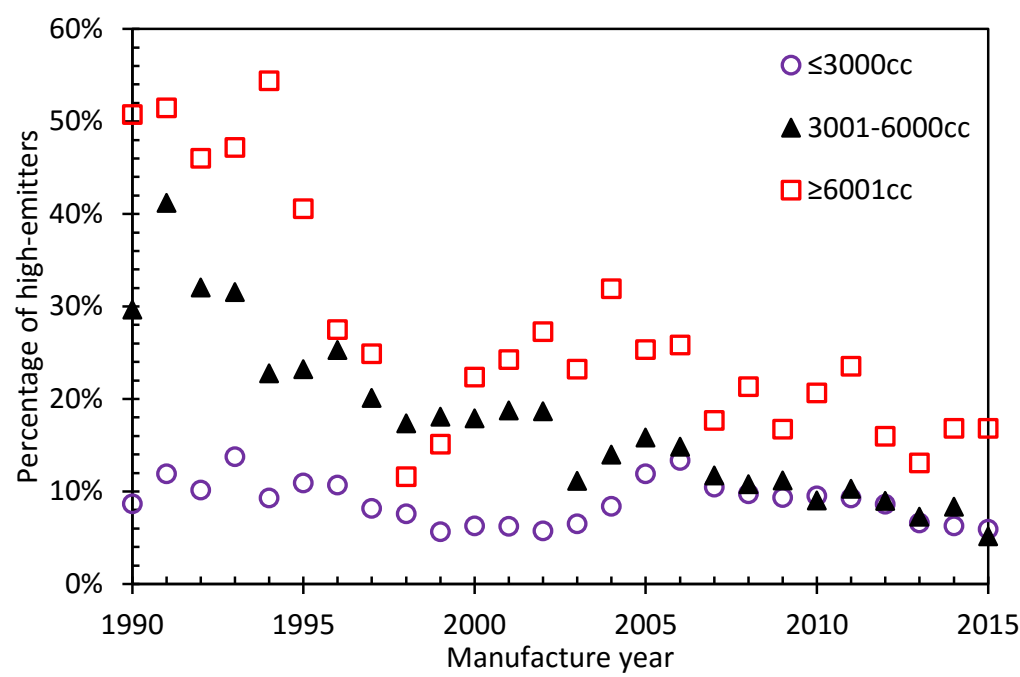

548

Fig. 7. Percentage of high-emitters in each manufacture year. 